\title{
Secuenciación y temporalización de los planes de estudio de la Mención en Educación Musical del Grado en Educación Primaria en las universidades españolas
}

\author{
Sequencing and timing of the study plans for the Music Education Mention in Primary \\ Education Teacher Degree in Spanish universities
}

\author{
Antonio Fernández-Jiménez \\ antoniferjim@ugr.es \\ Departamento de Didáctica de la Expresión Musical, Plástica y Corporal \\ Universidad de Granada \\ Granada, España \\ ORCID: http://orcid.org/0000-0002-5782-855X \\ Francisco A. Valdivia Sevilla \\ Departamento de Educación Artística \\ Universidad de Sevilla \\ Sevilla, España \\ ORCID: http://orcid.org/0000-0002-7195-5651
}

doi: 10.7203/LEEME.46.17619

Recibido: 12-06-2020 Aceptado: 29-07-2020. Contacto y correspondencia: Antonio Fernández Jiménez. Departamento de Didáctica de la Expresión Musical, Plástica y Corporal, Universidad de Granada, Facultad de Ciencias de la Educación, Campus de Cartuja, s/n, C.P. 18071 Granada. España.

\section{Resumen}

La normativa que regula los planes de estudio que forman a las futuras personas Graduadas en Educación Primaria recoge un módulo destinado a la formación en diferentes menciones, entre ellas, Música. Sin embargo, cada universidad realiza un diseño propio de la mención en cuanto a las asignaturas que la conforman, la secuencia de estas y la temporalización dentro del plan de estudios en general. Mediante un análisis cualitativo de los planes de estudios de las universidades españolas que han ofertado la Mención en Educación Musical en el curso académico 2019/2020, se detalla la secuencia y temporalización de cada uno de la Mención. Los resultados muestran un triple modelo en cuanto a la estructura temporal de la Mención, quedando unos articulados desde el $2^{\circ}$ hasta el $4^{\circ}$ curso, otros durante los cursos $3^{\circ}$ y $4^{\circ}$, y un tercer grupo que recoge la Mención solo en el $4^{\circ}$ curso. Además de ese triple modelo encontrado, se aprecia una destacable diversidad en cuanto a las asignaturas optativas que conforman la Mención, los créditos europeos de las mismas o el enfoque de la asignatura de formación didáctico y disciplinar en el ámbito de la Educación Musical.

Palabras clave: Maestro de Música; Educación Primaria; evaluación del plan de estudios; educación superior.

\begin{abstract}
The legislation that regulates the preparation programs that train future Primary Education teachers include a module aimed at training in different areas, including one for Music. However, it is each university that structures the mention in terms of the subjects that define it, the sequence of these and the timing within the preparation programs in general. Through a qualitative analysis of the preparation programs of the Spanish universities that have offered the Mention of Music Education in the 2019/2020 academic year, the sequence and timing of each of the study plans of the Mention is detailed. The results show a triple model regarding the time structure of the Mention, some of them being articulated from the $2^{\text {nd }}$ to the $4^{\text {th }}$ year, others during the $3^{\text {rd }}$ and $4^{\text {th }}$ year, and a third model that includes the Mention only in the $4^{\text {th }}$ year. However, and despite this triple model, there is a remarkable diversity in terms of the subjects that shape the Mention, the number of European credits of the latter or the focus of the compulsory subject in the field of Music Education.
\end{abstract}

Key words: Music teachers; Primary Education; program evaluation; higher education.

@ Antonio Fernández Jiménez y Francisco A. Valdivia Sevilla. The content of this article is the sole responsibility of the authors. The Revista Electrónica de LEEME and Universitat de València are not liable for any legal actions that may arise involving the article's content. Revista Electrónica de LEEME - Lista Electrónica Europea de Música en la Educación-. http://ojs.uv.es/index/php/LEEME/index ISSN: 1575-9563. Editores: Universidad de Valencia y Jesús Tejada. Visibilidad de esta revista: SCOPUS, Emerging Sources Citation Index (Clarivate), EBSCO, CINDOC (CSIC), Citefactor, COPAC, Dialnet, DICE (CSIC), DOAJ, e-revistas (CSIC), EBSCO Premier, ERIH+, Gale Cengage Learning, IN-RECS, IRESIE, LATINDEX, MIAR, OCLC Worldcat, RESH, REDIB, RILM Core Journals, SUDOC, ULRICHS. Esta revista es de acceso libre mediante licencia Creative Commons 4.0 CC by. Política de archivado: etiqueta verde SHERPA-ROMEO. 


\section{Introducción}

En el Grado de Educación Primaria que se imparte en las universidades españolas, "Mención" es la denominación del itinerario académico que componen una serie de asignaturas optativas que permiten la especialización en un área determinada de conocimiento. El presente artículo trata de establecer una categorización de los planes de estudio de la Mención en Educación Musical (MEM, en adelante) en el Estado Español atendiendo a su secuenciación y temporalidad.

La Orden ECI/3857/2007 de 27 de diciembre, por la que se establecen los requisitos para la verificación de los títulos universitarios oficiales que habiliten para el ejercicio de la profesión de Maestro en Educación Primaria recoge los criterios básicos que deben establecer las universidades para la planificación de los planes de estudio de las futuras personas Graduadas en Educación Primaria (Ministerio de Educación y Ciencia [MEC], 2007). Para adecuarse a la asignatura de Música (como parte del área de Educación Artística) dentro del currículo de Educación Primaria, la Orden ECI/3857/2007 propone la posibilidad de establecer menciones cualificadoras entre 30 y 60 créditos ECTS. El siguiente nivel de concreción compete a cada universidad, que establece el número de asignaturas y créditos. En este sentido, solamente se indica que el plan de estudio, de forma general, debe contar como mínimo con los siguientes módulos:

Tabla 1. Estructura del plan de estudio del Grado en Educación Primaria

\begin{tabular}{lll}
\hline \multicolumn{1}{c}{ Módulo } & Créditos ECTS \\
\hline Formación básica & 60 & \\
Didáctico y disciplinar & 100 & \\
Prácticum & 50 & \\
\hline
\end{tabular}

Fuente: Orden ECI/3857/2007 (MEC, 2007)

Los 30 créditos ECTS restantes hasta llegar a los 240 créditos ECTS que comprende la titulación corresponden a los créditos de la MEM. Por otro lado, el módulo dedicado a la formación didáctica y disciplinar recoge la materia 'Educación Musical, Plástica y Visual'. Sin embargo, en la Orden ECI/3857/2007 no se indica nada respecto a la secuenciación y temporalización que tendrá cada plan de estudio, en general, y cada mención, en particular, siendo cada universidad la que delimita esos dos aspectos para cada plan de estudio.

Desde este enfoque, no se han encontrado investigaciones similares más allá del estudio general que explicaba cómo sería el nuevo plan de estudio para el profesorado de Música en Educación Primaria tras la convergencia europea (Reyes, 2010) o investigaciones centradas en el plan de estudio de una universidad en concreto (v.g., Iotova y Siebenaler, 2018; López, Madrid y de Moya, 2017). Por tanto, resulta necesario este estudio para presentar una visión general del diseño estructural que cada universidad española desarrolla para la MEM del Grado

@ Antonio Fernández Jiménez y Francisco A. Valdivia Sevilla. The content of this article is the sole responsibility of the authors. The Revista Electrónica de LEEME and Universitat de València are not liable for any legal actions that may arise involving the article's content. Revista Electrónica de LEEME - Lista Electrónica Europea de Música en la Educación-. http://ojs.uv.es/index/php/LEEME/index ISSN: 1575-9563. Editores: Universidad de Valencia y Jesús Tejada. Visibilidad de esta revista: SCOPUS, Emerging Sources Citation Index (Clarivate), EBSCO, CINDOC (CSIC), Citefactor, COPAC, Dialnet, DICE (CSIC), DOAJ, e-revistas (CSIC), EBSCO Premier, ERIH+, Gale Cengage Learning, IN-RECS, IRESIE, LATINDEX, MIAR, OCLC Worldcat, RESH, REDIB, RILM Core Journals, SUDOC, ULRICHS. Esta revista es de acceso libre mediante licencia Creative Commons 4.0 CC by. Política de archivado: etiqueta verde SHERPA-ROMEO. 


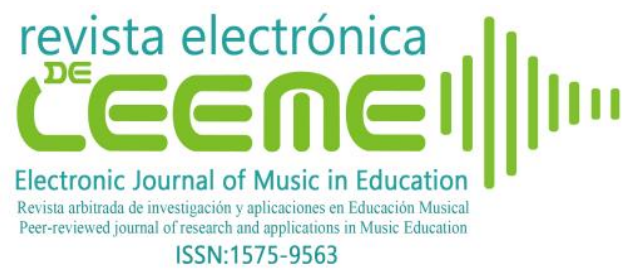

en Educación Primaria. De este modo, se pretende conocer si existe una línea común en el diseño de esa estructura por parte de las universidades españolas y qué asignaturas conforman la MEM de cada universidad.

\section{Método}

Se ha analizado un total de cuarenta y siete planes de estudios de aquellas universidades españolas que ofertan la MEM en el Grado en Educación Primaria en el curso académico 2019/2020. Para ello, se ha revisado la información alojada en la página web del plan de estudio de cada universidad, así como las guías docentes de las asignaturas optativas de la MEM y la asignatura sobre Educación Musical del módulo dedicado a la formación didáctica y disciplinar. Se utilizó una plantilla, de carácter cualitativo, elaborada por el proyecto ALFA II-0448-A ${ }^{1}$, y con resultados documentados en Aróstegui (2010, 2011). Dicha plantilla fue revisada y actualizada por el proyecto PROFMUS ${ }^{2}$ para adaptarla al marco actual de la titulación del Grado en Educación Primaria. Durante varios meses, se aplicó la plantilla a los planes de estudio analizados bajo un diseño de análisis documental, realizando un análisis descriptivo de contenido guiado por los diferentes campos recogidos en la plantilla, entre otros, seriación y articulación de la estructura curricular del plan de estudio, título de la asignatura, curso, cuatrimestre, módulo, créditos totales de la asignatura, áreas que la imparten, objetivos y contenidos. Esto ha permitido recopilar de manera ordenada las categorías encontradas en los planes de estudio objeto de análisis.

Los planes de estudio de las tres sedes de la Universidad de Castilla-La Mancha (Ciudad Real, Cuenca y Toledo) se han considerado como uno solo, ya que son idénticos (López et al., 2017). El mismo criterio se ha seguido respecto a las dos modalidades que ofrece la Universidad Católica San Antonio de Murcia (presencial y semipresencial). Sin embargo, los planes de estudio de la Universidad de Granada, en sus dos sedes (Granada y Melilla), se han contabilizado como dos, ya que incluyen asignaturas diferentes.

Según el inicio de las asignaturas de la MEM, podría hablarse de planes de estudio que, o bien la organizan de forma escalonada o concentran la formación específica en el último año del Grado. Entre los primeros, puede distinguirse a su vez entre los que empiezan en $2^{\circ}$ curso y los que lo hacen en $3^{\circ}$. De este modo, aparecen tres modelos de temporalización de la MEM. Se

\footnotetext{
${ }^{1}$ Se trata de un proyecto sobre la Evaluación de los Planes de Estudio de Formación del Profesorado de Música en Europa y América Latina, financiado por la Comisión Europea.

2 PROFMUS es el acrónimo del proyecto I+D+i: Formación de Profesorado y Música en la Sociedad y en la Economía del Conocimiento), financiado por el Ministerio de Economía y Competitividad. Tiene por objetivo general crear conocimiento, a partir de datos provenientes de la investigación, para determinar la adecuación de la formación del profesorado respecto a los retos que plantean las aulas de la educación obligatoria actual y documentar los cambios en las experiencias y vivencias del profesorado en relación con el desempeño de la profesión de educador musical.
}

@ Antonio Fernández Jiménez y Francisco A. Valdivia Sevilla. The content of this article is the sole responsibility of the authors. The Revista Electrónica de LEEME and Universitat de València are not liable for any legal actions that may arise involving the article's content. Revista Electrónica de LEEME - Lista Electrónica Europea de Música en la Educación-. http://ojs.uv.es/index/php/LEEME/index ISSN: 1575-9563. Editores: Universidad de Valencia y Jesús Tejada. Visibilidad de esta revista: SCOPUS, Emerging Sources Citation Index (Clarivate), EBSCO, CINDOC (CSIC), Citefactor, COPAC, Dialnet, DICE (CSIC), DOAJ, e-revistas (CSIC), EBSCO Premier, ERIH+, Gale Cengage Learning, IN-RECS, IRESIE, LATINDEX, MIAR, OCLC Worldcat, RESH, REDIB, RILM Core Journals, SUDOC, ULRICHS. Esta revista es de acceso libre mediante licencia Creative Commons 4.0 CC by. Política de archivado: etiqueta verde SHERPA-ROMEO. 
establecen, por tanto, tres categorías en función a la distribución de los créditos de la MEM a lo largo del Grado: una referida a los planes de estudio en la cual las asignaturas de la MEM se distribuyen entre los cursos $2^{\circ}, 3^{\circ}$ y $4^{\circ}$ del Grado; otra que engloba a los que reparten los créditos de la Mención entre $3^{\circ}$ y $4^{\circ}$; y la última que comprende los planes de estudio que concentran las asignaturas de MEM en el último curso.

Mención en un curso Mención en dos cursos Mención en tres cursos $\square$ ler curso

$$
\because 2^{\circ} \text { curso }
$$

$4^{\circ}$ curso

Figura 1. Modelos de temporalización de la MEM. Fuente: elaboración propia

Tabla 2. Distribución de los planes de estudio según las categorías de la temporalización de la MEM

\begin{tabular}{|c|c|}
\hline \multicolumn{2}{|c|}{ Mención en tres años $\left(2^{\circ}, 3^{\circ}\right.$ y $\left.4^{\circ}\right)$} \\
\hline Universidad Complutense de Madrid & Universidad Rey Juan Carlos \\
\hline Universidad de Huelva & Universitat Rovira i Virgili \\
\hline Universitat Ramon Llull & \\
\hline \multicolumn{2}{|c|}{ Mención en dos años $\left(3^{\circ}\right.$ y $\left.4^{\circ}\right)$} \\
\hline Universidad de Alicante & Universidad de Málaga \\
\hline Universidad de Burgos & Universidad de Oviedo \\
\hline Universidad de Cádiz & Universidad de Oviedo (Centro adscrito privado \\
\hline Universidad Camilo José Cela & Facultad Padre Ossó) \\
\hline Universidad Castilla-La Mancha & Universidad Pontificia de Salamanca \\
\hline Universidad Católica San Antonio de Murcia & Universidad Pública de Navarra \\
\hline Universidad Católica de Valencia & Universidad de Salamanca \\
\hline Universidad Francisco de Vitoria & Universidad de Santiago de Compostela \\
\hline Universidad de Gran Canaria & Universitat de València \\
\hline Universidad Internacional de La Rioja & Universidad de Valladolid \\
\hline Universidad de Jaén & Universitat de Vic \\
\hline Universidad de León & Universidad de Vigo \\
\hline \multicolumn{2}{|c|}{ Mención en el $4^{\circ}$ curso } \\
\hline Euskal Herriko Unibertsitatea (Universidad del País Vasco) & Universidad de Granada (sede Granada) \\
\hline Universitat Autònoma de Barcelona & Universidad de Granada (sede Melilla) \\
\hline Universidad Autónoma de Madrid & Universitat de les Illes Balears \\
\hline Universidad de Alcalá & Universitat Jaume I \\
\hline Universidad de Almería & Universidad de La Laguna \\
\hline Universitat de Barcelona & Universitat de Lleida \\
\hline Universidad de Córdoba & Universidad de Murcia \\
\hline Universidad de Córdoba (Centro adscrito Sagrado Corazón) & Universidad de Sevilla \\
\hline Universidad de Extremadura (sede Cáceres) & Universidad de Zaragoza \\
\hline Universitat de Girona & \\
\hline
\end{tabular}

Fuente: elaboración propia

@ Antonio Fernández Jiménez y Francisco A. Valdivia Sevilla. The content of this article is the sole responsibility of the authors. The Revista Electrónica de LEEME and Universitat de València are not liable for any legal actions that may arise involving the article's content. Revista Electrónica de LEEME - Lista Electrónica Europea de Música en la Educación-. http://ojs.uv.es/index/php/LEEME/index ISSN: 1575-9563. Editores: Universidad de Valencia y Jesús Tejada. Visibilidad de esta revista: SCOPUS, Emerging Sources Citation Index (Clarivate), EBSCO, CINDOC (CSIC), Citefactor, COPAC, Dialnet, DICE (CSIC), DOAJ, e-revistas (CSIC), EBSCO Premier, ERIH+, Gale Cengage Learning, IN-RECS, IRESIE, LATINDEX, MIAR, OCLC Worldcat, RESH, REDIB, RILM Core Journals, SUDOC, ULRICHS. Esta revista es de acceso libre mediante licencia Creative Commons 4.0 CC by. Política de archivado: etiqueta verde SHERPA-ROMEO. 


\section{Resultados}

A continuación, se exponen las tres categorías de forma detallada para cada plan de estudio de la MEM. Además, se incluye para cada plan de estudio, la asignatura relacionada con la música y perteneciente al módulo Didáctico y Disciplinar. Esta asignatura tiene un carácter obligatorio y aparece con diferente nombre según el plan de estudio, como, por ejemplo, 'Educación musical', 'Música en la educación primaria', 'Educación musical y su didáctica' o 'Expresión musical y su didáctica'. Solo se especificará el título de esta asignatura cuando tenga un carácter interdisciplinar o merezca ser destacada para la visión general del plan de estudio.

\subsection{Mención en tres años $\left(2^{\circ}, 3^{\circ}\right.$ y $\left.4^{\circ}\right)$}

Mención en tres cursos

$\square$ ler curso

$\square 2^{\circ}$ curso

3er curso

$4^{\circ}$ curso

Figura 2. Temporalización de la MEM en tres años. Fuente: elaboración propia

- Universidad Complutense de Madrid. Las asignaturas optativas (30 créditos ECTS) son:

- 2 $2^{\text {o: }}$ 'Formación vocal y su aplicación en el aula', en el segundo cuatrimestre del $2^{\circ}$ curso coincidiendo con la asignatura obligatoria 'Música en educación Primaria'.

- 3': 'Ritmo, movimiento y danza' y 'Formación instrumental y agrupaciones musicales escolares', cada una en un cuatrimestre.

- 4: 'La audición musical: análisis y metodología'.

- Universidad de Huelva. Las asignaturas optativas (30 créditos ECTS) son:

- $2^{\circ}$ : 'Lenguaje musical en primaria'. Se imparte en el primer cuatrimestre, coincidiendo con la asignatura de formación didáctica y disciplinar 'Música en la escuela' ( 6 créditos ECTS).

- 3': 'Formación instrumental' y 'Cantar en la escuela', ambas en el primer cuatrimestre, mientras que 'Tradiciones musicales del mundo' queda para el segundo.

- 4: 'Didáctica de la educación musical'.

@ Antonio Fernández Jiménez y Francisco A. Valdivia Sevilla. The content of this article is the sole responsibility of the authors. The Revista Electrónica de LEEME and Universitat de València are not liable for any legal actions that may arise involving the article's content. Revista Electrónica de LEEME - Lista Electrónica Europea de Música en la Educación-. http://ojs.uv.es/index/php/LEEME/index ISSN: 1575-9563. Editores: Universidad de Valencia y Jesús Tejada. Visibilidad de esta revista: SCOPUS, Emerging Sources Citation Index (Clarivate), EBSCO, CINDOC (CSIC), Citefactor, COPAC, Dialnet, DICE (CSIC), DOAJ, e-revistas (CSIC), EBSCO Premier, ERIH+, Gale Cengage Learning, IN-RECS, IRESIE, LATINDEX, MIAR, OCLC Worldcat, RESH, REDIB, RILM Core Journals, SUDOC, ULRICHS. Esta revista es de acceso libre mediante licencia Creative Commons 4.0 CC by. Política de archivado: etiqueta verde SHERPA-ROMEO. 
- Universitat Ramon Llull. Las asignaturas obligatorias relacionadas con música son dos y se imparten de forma alterna en $1^{\circ}$ ('Desarrollo de la expresión musical y su didáctica') y $3^{\circ}$ ('Educación a través de la plástica y la música y la educación física: proyecto interdisciplinario’). Las asignaturas optativas (30 créditos ECTS) son:

- 2o: 'Lenguaje musical aplicado', centrada en la educación del oído, en el desarrollo de los elementos del lenguaje musical y el uso de la tecnología, dentro de una metodología que favorece el flipped learning o aprendizaje inverso.

- 3': 'La voz y el cuerpo, elementos de producción y expresión musical'.

- 4': 'Tecnología y cultura musical', 'Didáctica y metodología, sonido y audición' y 'Creación, improvisación y dirección'.

- Universidad Rey Juan Carlos. Las asignaturas optativas (24 créditos ECTS) son:

- $2^{\text {o }}$ 'Educación musical II', en el segundo cuatrimestre, después de 'Educación musical I', asignatura obligatoria que se imparte en el primer cuatrimestre y suma 6 créditos a la MEM. El contenido de 'Educación musical II' es muy amplio, abarcando tanto lectura rítmica, flauta dulce, danza y expresión dramática, como teoría armónica, formas musicales y canto.

- 3: 'Educación musical III'. Continúa la formación armónica, e incluye la realización y ejecución de arreglos musicales, y el manejo de software de edición musical, además de otros contenidos que figuran en la guía docente como psicoacústica, dictado musical y dirección coral.

- 4: 'Educación musical IV y V'. La primera plantea relacionar los conocimientos previamente adquiridos con las principales corrientes pedagógicas de la didáctica de la música, pero no exclusivamente, puesto que también aborda el análisis musical, la canción, el cuento y la dramatización. La última asignatura parece orientada hacia la psicología y sociología de la música, pero los contenidos detallados en la guía docente revelan una importante presencia de la historia de la música, y también de teoría musical (formación de escalas) y educación auditiva-tonal.

- Universitat Rovira i Virgili. Las guías docentes no aclaran qué asignaturas optativas específicas se imparten en cada curso, pero sí que hay una en $2^{\circ}$, cuatro en $3^{\circ}$ y una en $4^{\circ}$, sumando 20 créditos ECTS. Los nombres de las asignaturas son: 'Audición: las historias de la música', 'Danza: la música en movimiento', 'Formación vocal y auditiva', 'Lenguaje musical', 'Práctica instrumental, creatividad e improvisación', 'Agrupaciones musicales' y 'Didáctica de la música y la danza en primaria'. Hay dos asignaturas

@ Antonio Fernández Jiménez y Francisco A. Valdivia Sevilla. The content of this article is the sole responsibility of the authors. The Revista Electrónica de LEEME and Universitat de València are not liable for any legal actions that may arise involving the article's content. Revista Electrónica de LEEME - Lista Electrónica Europea de Música en la Educación-. http://ojs.uv.es/index/php/LEEME/index ISSN: 1575-9563. Editores: Universidad de Valencia y Jesús Tejada. Visibilidad de esta revista: SCOPUS, Emerging Sources Citation Index (Clarivate), EBSCO, CINDOC (CSIC), Citefactor, COPAC, Dialnet, DICE (CSIC), DOAJ, e-revistas (CSIC), EBSCO Premier, ERIH+, Gale Cengage Learning, IN-RECS, IRESIE, LATINDEX, MIAR, OCLC Worldcat, RESH, REDIB, RILM Core Journals, SUDOC, ULRICHS. Esta revista es de acceso libre mediante licencia Creative Commons 4.0 CC by. Política de archivado: etiqueta verde SHERPA-ROMEO. 


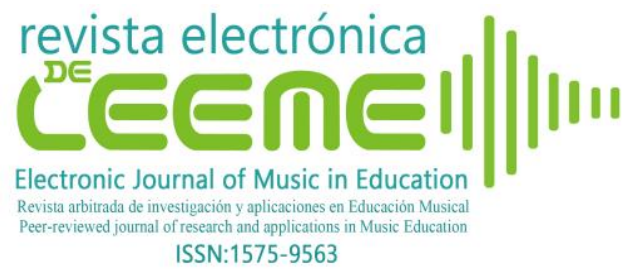

obligatorias, una de 12 créditos ECTS ( $2^{\circ}$ curso) y otra de 3 ( $4^{\circ}$ curso) que abordan la educación artística desde una perspectiva interdisciplinar.

\subsection{Mención en dos años $\left(3^{\circ}\right.$ y $\left.4^{\circ}\right)$}

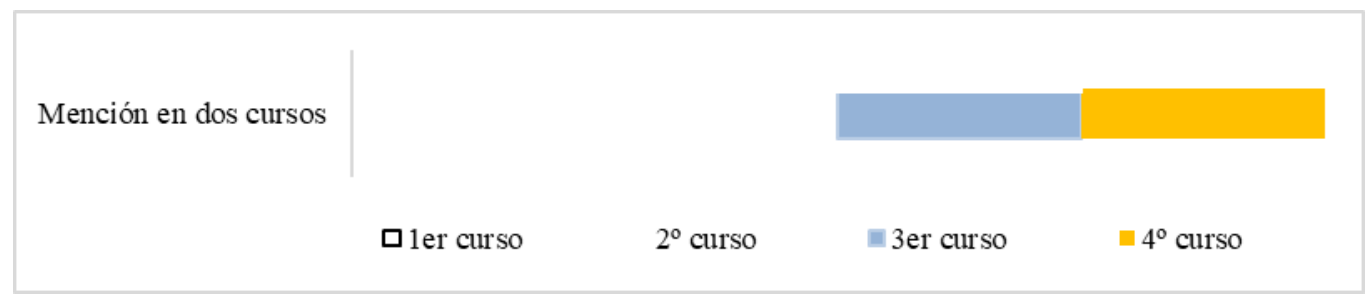

Figura 3. Temporalización de la MEM en dos años. Fuente: elaboración propia

Los planes de estudio de las siguientes universidades recogen las asignaturas propias de la MEM a partir del tercer curso, quedando repartidas entre este curso y el siguiente. Solo en uno de los planes de estudio de esta categoría aparecen todas aglutinadas en el curso $3^{\circ}$.

- Universidad de Alicante. La asignatura 'Prácticum III' (prácticas escolares) y el Trabajo Fin de Grado están vinculados directamente a la MEM. La asignatura obligatoria se imparte en $2^{\circ}$. Las asignaturas optativas ( 24 créditos ECTS) son:

- 3': 'Educación rítmica y movimiento' y 'Educación vocal y auditiva'.

- 4: 'La audición como elemento educativo', 'Historia de la música, patrimonio musical y folklore' y 'Educación musical y su didáctica'.

- Universidad de Burgos. La asignatura obligatoria se imparte en $2^{\circ}$. Las asignaturas optativas ( 30 créditos ECTS) son:

- 3': 'Educación vocal y auditiva', 'Formación instrumental' e 'Historia de la música'.

- 4: 'Agrupación coral', 'Didáctica de la expresión musical' y 'Composición y creación musical'.

- Universidad de Cádiz. La asignatura obligatoria se imparte en $2^{\circ}$. Las asignaturas optativas (24 créditos ECTS) son:

- 3: 'Expresión y creación musical a través de instrumentos' y 'Canto y agrupaciones vocales en el aula'.

- 4: 'La audición en los estilos musicales' y 'Pedagogía musical activa'.

- Universidad Camilo José Cela. La asignatura obligatoria se imparte en $4^{\circ}$. Las asignaturas optativas (30 créditos ECTS) son:

- $3^{\text {o: }}$ 'Lenguaje musical, ritmo y movimiento' e 'Historia de la música y tendencias actuales'.

@ Antonio Fernández Jiménez y Francisco A. Valdivia Sevilla. The content of this article is the sole responsibility of the authors. The Revista Electrónica de LEEME and Universitat de València are not liable for any legal actions that may arise involving the article's content. Revista Electrónica de LEEME - Lista Electrónica Europea de Música en la Educación-. http://ojs.uv.es/index/php/LEEME/index ISSN: 1575-9563. Editores: Universidad de Valencia y Jesús Tejada. Visibilidad de esta revista: SCOPUS, Emerging Sources Citation Index (Clarivate), EBSCO, CINDOC (CSIC), Citefactor, COPAC, Dialnet, DICE (CSIC), DOAJ, e-revistas (CSIC), EBSCO Premier, ERIH+, Gale Cengage Learning, IN-RECS, IRESIE, LATINDEX, MIAR, OCLC Worldcat, RESH, REDIB, RILM Core Journals, SUDOC, ULRICHS. Esta revista es de acceso libre mediante licencia Creative Commons 4.0 CC by. Política de archivado: etiqueta verde SHERPA-ROMEO. 
- 4': 'Percepción musical y expresión vocal', 'Formación instrumental y agrupaciones musicales escolares' y 'TICS aplicadas a la educación musical'.

- Universidad de Castilla-La Mancha. Solo las dos primeras asignaturas cuentan con 6 créditos ECTS, quedando las cuatro restantes con 4,5. La asignatura obligatoria se imparte en $2^{\circ}$. Las asignaturas optativas ( 24 créditos ECTS) son:

- 3: 'Lenguajes musicales', 'Expresión instrumental' y 'Didáctica de la música'.

- 4: 'Expresión vocal y corporal', 'Historia de la música' y 'Prácticas musicales creativas'. Esta última propone el desarrollo de la creatividad a partir de la experiencia grupal.

- Universidad Católica San Antonio de Murcia. Tanto las asignaturas optativas como la obligatoria, 'Enseñanza y aprendizaje de la expresión musical', se imparten en $3^{\circ}$. Las asignaturas optativas (30 créditos ECTS) son:

- 3': 'Expresión instrumental', 'Formación vocal', 'Lenguaje musical', 'Metodologías de la enseñanza musical' y 'Desarrollo psicomotor y expresión corporal'.

- Universidad Católica de Valencia. La asignatura obligatoria se imparte en $2^{\circ}$. Las asignaturas optativas (30 créditos ECTS) son:

- 30: 'Didáctica de la educación musical' y 'Espacios sonoros de diversidad e interculturalidad' (que a pesar de su nombre tiene contenidos similares a la materia sobre formación vocal y auditiva).

- 4: 'Desarrollo de la creación e improvisación musical', 'Ritmo y movimiento' y 'Tecnologías de la información y la comunicación aplicadas a la educación musical'.

- Universidad Francisco de Vitoria. La asignatura obligatoria, 'Educación artística y su didáctica', se imparte en $1^{\circ}$. Las asignaturas optativas ( 24 créditos ECTS) son:

- $3^{\text {o: }}$ 'Lenguaje musical' y 'Lectura y entonación'. Ambas tienen un marcado contenido técnico, centrándose la segunda más en el solfeo.

- 4': 'Canto polifónico' y 'Formación rítmica y danza', ambas con un enfoque basado en un modelo muy tradicional.

- Universidad de Gran Canaria. La asignatura obligatoria se imparte en $2^{\circ}$. Las asignaturas optativas ( 30 créditos ECTS) son:

- 3': 'Lenguaje musical', 'Didáctica de la expresión musical' y 'Nuevas tecnologías aplicadas a la didáctica musical'.

- 4': 'Agrupaciones musicales', 'Formación vocal y auditiva', 'Historia de la música y la audición’, y 'Lenguaje musical y sus aplicaciones didácticas'.

@ Antonio Fernández Jiménez y Francisco A. Valdivia Sevilla. The content of this article is the sole responsibility of the authors. The Revista Electrónica de LEEME and Universitat de València are not liable for any legal actions that may arise involving the article's content. Revista Electrónica de LEEME - Lista Electrónica Europea de Música en la Educación-. http://ojs.uv.es/index/php/LEEME/index ISSN: 1575-9563. Editores: Universidad de Valencia y Jesús Tejada. Visibilidad de esta revista: SCOPUS, Emerging Sources Citation Index (Clarivate), EBSCO, CINDOC (CSIC), Citefactor, COPAC, Dialnet, DICE (CSIC), DOAJ, e-revistas (CSIC), EBSCO Premier, ERIH+, Gale Cengage Learning, IN-RECS, IRESIE, LATINDEX, MIAR, OCLC Worldcat, RESH, REDIB, RILM Core Journals, SUDOC, ULRICHS. Esta revista es de acceso libre mediante licencia Creative Commons 4.0 CC by. Política de archivado: etiqueta verde SHERPA-ROMEO. 
- Universidad Internacional de La Rioja. Las asignaturas obligatorias que se imparten en $1^{\circ}$ y $2^{\circ}$ son respectivamente 'Conocimiento musical' y 'Educación musical y su didáctica'. Las asignaturas optativas (30 créditos ECTS) son:

- 3 : 'La educación musical a lo largo de la historia' y 'La educación musical y la formación integral'.

- 4: 'Las tecnologías de la información y la comunicación aplicadas a la educación musical', 'Formación instrumental y vocal' y 'Fundamentos de armonía y de análisis musical'.

- Universidad de Jaén. La asignatura obligatoria que se cursa en $1^{\circ}$ tiene 7 créditos ECTS y forma parte de la MEM. Las asignaturas optativas (24 créditos ECTS) son:

- 3: 'Interpretación y creación instrumental', 'Planificación y recursos para la iniciación musical'.

- 4 indistintamente: 'Audición y contextos musicales' e 'Interpretación y creación vocal'.

- Universidad de León. La asignatura obligatoria se imparte en $2^{\circ}$. Las asignaturas optativas (22 créditos ECTS) son:

- 30: 'Audición musical activa'.

- 4': 'Didáctica de la expresión musical', 'Formación instrumental y agrupaciones musicales escolares', 'Formación vocal, agrupación y dirección coral', 'Formación rítmica y danza' y 'Lenguaje musical'.

- Universidad de Málaga. La asignatura obligatoria tiene 6 créditos ECTS, se cursa en $1^{\circ} \mathrm{y}$ forma parte de la MEM. Las asignaturas optativas (24 créditos ECTS) son:

- 3: 'Formación instrumental para la Educación Primaria', 'Historia de la música' y 'Formación rítmica y danza'.

- 4: 'Formación vocal y auditiva para la Educación Primaria'.

- Universidad de Oviedo. La asignatura obligatoria se imparte en $3^{\circ}$ y es anual. Las asignaturas optativas (30 créditos ECTS) son:

- 3: 'Patrimonio artístico musical en el aula' y 'Lenguaje musical'.

- 4: 'Formación vocal y auditiva', 'Formación rítmica y danza' y 'Formación instrumental y agrupaciones musicales'. Además, está 'Prácticum IV Mención Educación Musical', que son las prácticas escolares específicas de la MEM.

- Universidad de Oviedo (Centro adscrito privado Facultad Padre Ossó). Igual que la anterior, con la única diferencia de que se imparte 'Intervención educativa

@ Antonio Fernández Jiménez y Francisco A. Valdivia Sevilla. The content of this article is the sole responsibility of the authors. The Revista Electrónica de LEEME and Universitat de València are not liable for any legal actions that may arise involving the article's content. Revista Electrónica de LEEME - Lista Electrónica Europea de Música en la Educación-. http://ojs.uv.es/index/php/LEEME/index ISSN: 1575-9563. Editores: Universidad de Valencia y Jesús Tejada. Visibilidad de esta revista: SCOPUS, Emerging Sources Citation Index (Clarivate), EBSCO, CINDOC (CSIC), Citefactor, COPAC, Dialnet, DICE (CSIC), DOAJ, e-revistas (CSIC), EBSCO Premier, ERIH+, Gale Cengage Learning, IN-RECS, IRESIE, LATINDEX, MIAR, OCLC Worldcat, RESH, REDIB, RILM Core Journals, SUDOC, ULRICHS. Esta revista es de acceso libre mediante licencia Creative Commons 4.0 CC by. Política de archivado: etiqueta verde SHERPA-ROMEO. 
para la educación musical' en $3^{\circ}$ en lugar de 'Patrimonio artístico musical en el aula'.

- Universidad Pontificia de Salamanca. La asignatura obligatoria se imparte en $3^{\circ}$. Las asignaturas optativas ( 28 créditos ECTS) son:

- $3^{\text {o }}$ : (12 créditos ECTS): 'Lenguaje musical' y 'Formación vocal y auditiva'.

- 4: (16 créditos ECTS): 'Didáctica de la expresión musical', 'Historia de la música' y 'Formación y agrupación instrumental'.

- Universidad Pública de Navarra. Hay prácticas externas específicas, 'Prácticas escolares 2: Música', que aporta 15 créditos ECTS. Hay una asignatura de formación básica en $1^{\circ}$, 'Artes y patrimonio artístico', y una obligatoria en $3^{\circ}$, 'Educación artística II', que comparten contenidos con el área de Educación Plástica. Las asignaturas optativas (21 créditos ECTS) son:

- 3': 'Métodos tradicionales de educación musical' y 'Métodos y modelos actuales de educación musical'.

- 4': 'Repertorio musical en la escuela' y 'Desarrollo curricular y de investigación para la educación musical'.

- Universidad de Salamanca. La asignatura obligatoria se imparte en $2^{\circ}$. Las asignaturas optativas (30 créditos ECTS) son:

- 3': 'Formación vocal y auditiva' y 'Didáctica de la expresión musical'.

- 4: 'Formación rítmica y danza', 'Formación instrumental', 'Creación y selección de repertorio musical para el aula', 'Educación auditiva' y 'Música y danza para la diversidad'.

- Universidad de Santiago de Compostela. La asignatura obligatoria se imparte en $2^{\circ}$. Las asignaturas optativas (18 créditos ECTS) son:

- 3': 'Educación vocal y auditiva' y 'Lenguaje musical'.

- 4: 'Formación rítmica e instrumental' y 'Procesos y proyectos didácticos de educación musical'.

- Universitat de València. La asignatura obligatoria se imparte en $1^{\circ}$. Las asignaturas optativas (30 créditos ECTS) son:

- 3: 'Música y movimiento', 'Audición musical', 'Educación instrumental' y 'Música y tecnologías de la información'.

- 4: 'Educación vocal' y 'Didáctica musical'.

- Universidad de Valladolid. Las asignaturas obligatorias de $2^{\circ}$ son 'Fundamentos y estrategias didácticas en la educación musical' y 'Creación artística, cultura visual y musical'. Las asignaturas optativas (30 créditos ECTS) son:

@ Antonio Fernández Jiménez y Francisco A. Valdivia Sevilla. The content of this article is the sole responsibility of the authors. The Revista Electrónica de LEEME and Universitat de València are not liable for any legal actions that may arise involving the article's content. Revista Electrónica de LEEME - Lista Electrónica Europea de Música en la Educación-. http://ojs.uv.es/index/php/LEEME/index ISSN: 1575-9563. Editores: Universidad de Valencia y Jesús Tejada. Visibilidad de esta revista: SCOPUS, Emerging Sources Citation Index (Clarivate), EBSCO, CINDOC (CSIC), Citefactor, COPAC, Dialnet, DICE (CSIC), DOAJ, e-revistas (CSIC), EBSCO Premier, ERIH+, Gale Cengage Learning, IN-RECS, IRESIE, LATINDEX, MIAR, OCLC Worldcat, RESH, REDIB, RILM Core Journals, SUDOC, ULRICHS. Esta revista es de acceso libre mediante licencia Creative Commons 4.0 CC by. Política de archivado: etiqueta verde SHERPA-ROMEO. 
- 3: 'Formas de expresión musical' y 'Música, cultura y diversidad'.

- 4': 'Didáctica de la expresión musical', 'Conjunto vocal e instrumental' y 'Tecnologías de la información y la comunicación aplicadas a la educación musical'.

- Universitat de Vic. Las asignaturas optativas (30 créditos ECTS) son: Son cinco asignaturas y parece que el alumnado tiene libertad para repartirlas entre el 3er y $4^{\circ}$ curso. Se trata de: 'Audición, repertorio y educación estética', 'Fundamentos de la didáctica de la música', 'Música y cuerpo', 'Práctica instrumental en el aula' y 'Canción y voz'. La asignatura obligatoria se da en $1^{\circ}$.

- Universidad de Vigo. La asignatura obligatoria se imparte en $2^{\circ}$. Se ofertan 5 asignaturas de Música en $3^{\circ}$ y $4^{\circ}$ cursos, de las cuales deberán cursar 4 (total 24 créditos ECTS) para obtener la MEM. Dentro de la asignatura 'Prácticum anual' ( $4^{\circ}$ curso) se dedican 6 créditos ECTS a prácticas escolares propias de la MEM. Las asignaturas optativas (30 créditos ECTS) son:

- 3: 'Agrupacións instrumentais para a escola primaria', 'Novas tecnoloxías para a educación musical en primaria' y 'Técnica vocal e práctica coral'.

- 4: 'Música nas culturas' y 'Expresión corporal e danza'.

\subsection{Mención en el $4^{\circ}$ curso}

Mención en un curso

口1er curso $\quad 2^{\circ}$ curso $\quad$ 3er curso $\quad 4^{\circ}$ curso

Figura 4. Temporalización de la MEM en un año. Fuente: elaboración propia

- Euskal Herriko Unibertsitatea (Universidad del País Vasco). Las asignaturas optativas (30 créditos ECTS) son: 'Educación auditiva', 'Formación vocal y canto', 'Formación instrumental', 'Interacción de lenguajes. La cultura audiovisual. Revisión desde una perspectiva de género', 'Ritmo, movimiento y danza'. La asignatura obligatoria se imparte en $2^{\circ}$.

- Universitat Autònoma de Barcelona. Las asignaturas optativas (30 créditos ECTS) son: 'Didáctica de la música I y II', 'Análisis, audición y su didáctica', 'Lenguaje musical' y 'Voz, canción, dirección y su didáctica'. Las obligatorias son tres, una en cada curso anterior: 'Comunicación e interacción educativa I',

@ Antonio Fernández Jiménez y Francisco A. Valdivia Sevilla. The content of this article is the sole responsibility of the authors. The Revista Electrónica de LEEME and Universitat de València are not liable for any legal actions that may arise involving the article's content. Revista Electrónica de LEEME - Lista Electrónica Europea de Música en la Educación-. http://ojs.uv.es/index/php/LEEME/index ISSN: 1575-9563. Editores: Universidad de Valencia y Jesús Tejada. Visibilidad de esta revista: SCOPUS, Emerging Sources Citation Index (Clarivate), EBSCO, CINDOC (CSIC), Citefactor, COPAC, Dialnet, DICE (CSIC), DOAJ, e-revistas (CSIC), EBSCO Premier, ERIH+, Gale Cengage Learning, IN-RECS, IRESIE, LATINDEX, MIAR, OCLC Worldcat, RESH, REDIB, RILM Core Journals, SUDOC, ULRICHS. Esta revista es de acceso libre mediante licencia Creative Commons 4.0 CC by. Política de archivado: etiqueta verde SHERPA-ROMEO. 
'Educación musical y visual' y 'Educación musical, visual y aprendizaje', y son de naturaleza interdisciplinar.

- Universidad Autónoma de Madrid. Las asignaturas optativas (21 créditos ECTS) son: 'Formación musical I: conjunto instrumental y flauta de pico', 'Formación musical II: formación rítmica y danza', 'Formación musical III: formación vocal y auditiva' y 'Formación musical IV: nuevas tecnologías aplicadas a la educación musical'. Hay prácticas escolares específicas con 12 créditos ECTS. La asignatura obligatoria se imparte en $3^{\circ}$.

- Universidad de Alcalá. Las asignaturas optativas (12 créditos ECTS) son: 'Cómo escuchar la música' y 'La creación musical en el aula de primaria'. La asignatura obligatoria se da en $2^{\circ}$, 'Formación vocal e instrumental: recursos didácticos'. Las prácticas escolares son específicas de música. Aunque no se aclara el número mínimo de asignaturas para obtener la Mención, los 24 créditos ECTS que establece como requisitos se podrían interpretar según el siguiente desglose: asignatura obligatoria de Música (6 créditos ECTS), más 2 asignaturas optativas de Música (12 créditos ECTS), más otros 6 créditos ECTS que podrían corresponder a la asignatura optativa sobre Educación Plástica (ya que la Mención es "Artes en Educación Primaria”).

- Universidad de Almería. Las asignaturas optativas (24 créditos ECTS) son: 'Las artes plásticas en la educación', 'Didáctica de la expresión musical', 'Didáctica y percepción musical', 'Didáctica de la expresión y comunicación musical', 'Intervención musical en alumnado con necesidades educativas especiales'. La asignatura obligatoria se imparte en $1^{\circ}$.

- Universitat de Barcelona. Las asignaturas optativas (27 créditos ECTS) son: 'Didáctica de la música', 'Música y movimiento: formación y didáctica', 'La voz y la canción: formación y didáctica', 'Conjunto instrumental escolar', 'Instrumentos musicales: formación y didáctica', 'Educación del oído y audiciones musicales'. La asignatura obligatoria se imparte en $3^{\circ}$.

- Universidad de Córdoba. Las asignaturas optativas (24 créditos ECTS) son: 'El lenguaje musical a través del movimiento y los instrumentos escolares', 'Formación auditiva y expresión vocal', 'Análisis y creación musical aplicados al repertorio escolar' y 'Expresión musical colectiva. Métodos de intervención educativa'. La asignatura obligatoria se imparte en $1^{\circ}$.

- Universidad de Córdoba (Centro adscrito Sagrado Corazón). Las asignaturas optativas (24 créditos ECTS) son: 'Análisis del lenguaje musical. Aplicación a

@ Antonio Fernández Jiménez y Francisco A. Valdivia Sevilla. The content of this article is the sole responsibility of the authors. The Revista Electrónica de LEEME and Universitat de València are not liable for any legal actions that may arise involving the article's content. Revista Electrónica de LEEME - Lista Electrónica Europea de Música en la Educación-. http://ojs.uv.es/index/php/LEEME/index ISSN: 1575-9563. Editores: Universidad de Valencia y Jesús Tejada. Visibilidad de esta revista: SCOPUS, Emerging Sources Citation Index (Clarivate), EBSCO, CINDOC (CSIC), Citefactor, COPAC, Dialnet, DICE (CSIC), DOAJ, e-revistas (CSIC), EBSCO Premier, ERIH+, Gale Cengage Learning, IN-RECS, IRESIE, LATINDEX, MIAR, OCLC Worldcat, RESH, REDIB, RILM Core Journals, SUDOC, ULRICHS. Esta revista es de acceso libre mediante licencia Creative Commons 4.0 CC by. Política de archivado: etiqueta verde SHERPA-ROMEO. 
la flauta dulce', 'El movimiento a través de la expresión musical y su didáctica', 'Formación vocal y auditiva y efectos psico-educativos de la terapia musical' y 'El lenguaje musical a través de los instrumentos escolares'. La asignatura obligatoria se imparte en $1^{\circ}$.

- Universidad de Extremadura (sede Cáceres). Las asignaturas optativas (24 créditos ECTS) son: 'Fundamentos musicales y su didáctica', 'Interpretación musical y su didáctica I y II', 'Música, movimiento y educación'. La asignatura obligatoria de $3^{\circ}$ 'Fundamentos de la expresión musical en educación primaria' tiene un título muy similar a la primera asignatura optativa.

- Universitat de Girona. Las asignaturas optativas (21 créditos ECTS) son: 'Educación de la voz y canción. Desarrollo de capacidades musicales', 'Práctica instrumental y creatividad', 'Oído y comprensión musical y uso de las tecnologías audiovisuales', 'Didáctica de la educación musical', 'Dirección coral e instrumental', 'Historia de la música: evolución, renovación y estilos' y 'Didáctica de la música II'. Todas son de 3 créditos ECTS. La asignatura obligatoria de $2^{\circ}$, 'Educación musical, plástica y visual' tiene 5 créditos ECTS y es de carácter interdisciplinar. La información disponible está desactualizada. Se mezcla información del plan de estudio 2018-2019 con el del 2019-2020.

- Universidad de Granada (sede Granada). Las asignaturas optativas (24 créditos ECTS) son: 'La audición musical en la escuela', 'Práctica con instrumentos musicales en la escuela', 'Recursos musicales para la escuela' y 'Educación vocal y práctica coral'. Los créditos restantes para la MEM se completan con parte de los créditos de la asignatura 'Prácticum II'. La asignatura obligatoria se imparte en $3^{\circ}$.

- Universidad de Granada (sede Melilla). Las asignaturas optativas (24 créditos ECTS) son: 'Didáctica de la expresión musical', 'Formación instrumental y agrupaciones musicales', 'Formación vocal y auditiva' y 'Lenguaje musical'. Los créditos restantes para la MEM se completan con parte de los créditos de la asignatura 'Prácticum II'. La asignatura obligatoria se imparte en $3^{\circ}$.

- Universitat de les Illes Balears. Las asignaturas optativas (11 créditos ECTS) son: 'Formació Musical', 'Agrupaciones instrumentales' (3 créditos ECTS) y 'Pràctiques de menció: educació musical i artística' ( 9 créditos ECTS). La obligatoria se imparte en $3^{\circ}$.

- Universitat Jaume I. La asignatura optativa (6 créditos ECTS) es: 'Nuevas tecnologías aplicadas a la música'. La MEM se completa con las prácticas

@ Antonio Fernández Jiménez y Francisco A. Valdivia Sevilla. The content of this article is the sole responsibility of the authors. The Revista Electrónica de LEEME and Universitat de València are not liable for any legal actions that may arise involving the article's content. Revista Electrónica de LEEME - Lista Electrónica Europea de Música en la Educación-. http://ojs.uv.es/index/php/LEEME/index ISSN: 1575-9563. Editores: Universidad de Valencia y Jesús Tejada. Visibilidad de esta revista: SCOPUS, Emerging Sources Citation Index (Clarivate), EBSCO, CINDOC (CSIC), Citefactor, COPAC, Dialnet, DICE (CSIC), DOAJ, e-revistas (CSIC), EBSCO Premier, ERIH+, Gale Cengage Learning, IN-RECS, IRESIE, LATINDEX, MIAR, OCLC Worldcat, RESH, REDIB, RILM Core Journals, SUDOC, ULRICHS. Esta revista es de acceso libre mediante licencia Creative Commons 4.0 CC by. Política de archivado: etiqueta verde SHERPA-ROMEO. 
específicas de música (26 créditos ECTS). Esta carencia de asignaturas en la Mención se compensa también con la presencia de dos asignaturas obligatorias en $2^{\circ}$ y $3^{\circ}$, que son respectivamente 'Música' y 'Didáctica de la expresión musical en educación primaria'. No obstante, no queda claro si algunas asignaturas de la MEM son asignaturas obligatorias u optativas, pues en diversas partes de la página web se contradicen estos datos.

- Universidad de La Laguna. Las asignaturas optativas (18 créditos ECTS) son: 'Interpretación y creación musical', 'Lenguaje musical y sus contextos' y 'Didáctica de la percepción y expresión musical'. La asignatura obligatoria se imparte en $2^{\circ}$.

- Universitat de Lleida. Las asignaturas optativas (18 créditos ECTS) son: 'Educación musical I y II'. Las asignaturas obligatorias de $1^{\circ}$ y $3^{\circ}$ son 'Música y su didáctica' (6 ECTS) y 'Didáctica de la educación artística' (9 créditos ECTS).

- Universidad de Murcia. Las asignaturas optativas (30 créditos ECTS) son: 'Lenguaje musical y expresión vocal', 'Expresión instrumental', 'Estilos y tradiciones musicales', 'Música y movimiento', 'Métodos y recursos para la educación musical', Hay otras cuatro optativas de 3 créditos ECTS cada una que son 'Música y TIC', 'Taller de creatividad musical', 'Musicoterapia' y 'Formación coral'. De estas nueve asignaturas optativas, hay cuatro que son elegibles. El alumnado solo cursará siete asignaturas. La asignatura obligatoria se imparte en $3^{\circ}$.

- Universidad de Sevilla. Las asignaturas optativas (30 créditos ECTS) son: 'Formación instrumental', 'Formación vocal y auditiva', 'Historia de la música y del folklore', 'Didáctica de la música' y 'Práctica y fundamentos musicales'. La asignatura obligatoria se imparte en $3^{\circ}$.

- Universidad de Zaragoza. Las asignaturas optativas (30 créditos ECTS) son: 'Audición musical activa', 'Formación instrumental', 'Formación vocal y auditiva', 'Lenguajes de la música' y 'Música y movimiento expresivo'. También hay prácticas específicas con 10 créditos ECTS. La asignatura obligatoria se imparte en $3^{\circ}$.

@ Antonio Fernández Jiménez y Francisco A. Valdivia Sevilla. The content of this article is the sole responsibility of the authors. The Revista Electrónica de LEEME and Universitat de València are not liable for any legal actions that may arise involving the article's content. Revista Electrónica de LEEME - Lista Electrónica Europea de Música en la Educación-. http://ojs.uv.es/index/php/LEEME/index ISSN: 1575-9563. Editores: Universidad de Valencia y Jesús Tejada. Visibilidad de esta revista: SCOPUS, Emerging Sources Citation Index (Clarivate), EBSCO, CINDOC (CSIC), Citefactor, COPAC, Dialnet, DICE (CSIC), DOAJ, e-revistas (CSIC), EBSCO Premier, ERIH+, Gale Cengage Learning, IN-RECS, IRESIE, LATINDEX, MIAR, OCLC Worldcat, RESH, REDIB, RILM Core Journals, SUDOC, ULRICHS. Esta revista es de acceso libre mediante licencia Creative Commons 4.0 CC by. Política de archivado: etiqueta verde SHERPA-ROMEO. 


\section{Análisis de resultados}

La estructura de la MEM suele articularse en torno a cuatro ejes o ámbitos de la educación musical, como son: la música y sus lenguajes, expresión vocal y auditiva, expresión instrumental, música y movimiento. Esto refleja la pervivencia de un enfoque centrado en la transmisión de contenidos disciplinares característicos de un enfoque tradicional, siendo la práctica instrumental la más presente en los planes de estudio del profesorado de Música de Educación Primaria (Belletich, Ángel-Alvarado y Wilhelmi, 2017). En otros casos, se observa un planteamiento más abierto dentro de la formación y disciplinar, por ejemplo, en asignaturas como 'Tradiciones musicales en el mundo', 'Tecnología y cultura musical', 'Creación, improvisación y dirección' o 'Pedagogía musical activa'.

La asignatura 'Didáctica de la música' o 'Didáctica de la expresión musical' aparece, aproximadamente, en la mitad de los planes de estudio. En el resto de las universidades, no se contempla una asignatura específica de didáctica de la música, sino que ésta se incluye como contenido en el resto de las asignaturas optativas, para trabajar la didáctica de manera más concreta desde cada uno de los ámbitos de la expresión musical.

En cuanto a la asignatura del ámbito de la música, perteneciente al módulo didáctico y disciplinar, y que aquí se ha mencionado como asignatura obligatoria, se observa que la mayoría de los planes de estudio la temporalizan en los primeros cursos y bajo un título enfocado a la música en el contexto de la Educación Primaria. En otros planes de estudio, aparece unida al campo de la Educación Plástica y Visual para tratar la Educación Artística de una manera interdisciplinar, como en el caso de la Universitat Rovira i Virgili y la Autònoma de Barcelona.

\subsection{Mención en tres años $\left(2^{\circ}, 3^{\circ}\right.$ y $\left.4^{\circ}\right)$}

Los títulos de la mayoría de las asignaturas que conforman los planes de estudio son bastante ilustrativos respecto a sus contenidos. Este diseño es el que más se asemeja a la secuenciación de la antigua especialidad, como los de la Universidad Complutense de Madrid o la Universidad de Huelva. Sin embargo, hay asignaturas, como las de la Universidad Rey Juan Carlos, que adoptan un título genérico para todo el plan de estudios, presentando, además, una mezcla muy amplia de contenidos en cada una de ellas.

La Universidad Rey Juan Carlos y la Universitat Ramon Llull son las únicas que dedican asignaturas a las nuevas tecnologías, si bien de manera más dedicada en el caso de la segunda. Esta misma universidad incluye una asignatura de marcado carácter creativo, 'Creación, improvisación y dirección', mientras que la Universitat Rovira i Virgili dispone de 'Práctica instrumental, creatividad e improvisación'.

@ Antonio Fernández Jiménez y Francisco A. Valdivia Sevilla. The content of this article is the sole responsibility of the authors. The Revista Electrónica de LEEME and Universitat de València are not liable for any legal actions that may arise involving the article's content. Revista Electrónica de LEEME - Lista Electrónica Europea de Música en la Educación-. http://ojs.uv.es/index/php/LEEME/index ISSN: 1575-9563. Editores: Universidad de Valencia y Jesús Tejada. Visibilidad de esta revista: SCOPUS, Emerging Sources Citation Index (Clarivate), EBSCO, CINDOC (CSIC), Citefactor, COPAC, Dialnet, DICE (CSIC), DOAJ, e-revistas (CSIC), EBSCO Premier, ERIH+, Gale Cengage Learning, IN-RECS, IRESIE, LATINDEX, MIAR, OCLC Worldcat, RESH, REDIB, RILM Core Journals, SUDOC, ULRICHS. Esta revista es de acceso libre mediante licencia Creative Commons 4.0 CC by. Política de archivado: etiqueta verde SHERPA-ROMEO. 


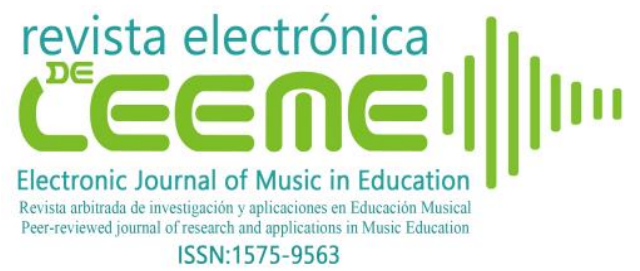

Por otra parte, la Universidad Complutense de Madrid ofrece una asignatura que hace énfasis en el movimiento: 'Ritmo, movimiento y danza'. En este sentido, la Universitat Rovira i Virgili incluye dos: 'Danza: la música en movimiento' y 'Didáctica de la música y la danza en primaria'.

Casi todas las asignaturas son de 6 créditos ECTS, con la excepción expresa de la Universitat Rovira i Virgili, donde las asignaturas se distinguen por tener solo 3 créditos ECTS cada una, lo cual puede suponer una limitación a la hora de profundizar en estos contenidos tan diversos. Por otro lado, el hecho de que sean siete las asignaturas optativas, más las dos obligatorias, demuestra una preocupación por la búsqueda integral de la formación. La Universitat Ramon Llull tiene la peculiaridad de que una de las dos asignaturas obligatorias de música se imparte en $1^{\circ}$, de tal modo que para el alumnado de la MEM hay asignaturas con contenido musical en todos los cursos de la carrera.

\subsection{Mención en dos años $\left(3^{\circ}\right.$ y $\left.4^{\circ}\right)$}

La mayor parte de asignaturas de música están todavía vinculadas a un enfoque tradicional de la enseñanza-aprendizaje musical y, aunque presentan las clásicas pedagogías musicales activas, apenas trabajan otros modelos educativos actuales, como los recopilados por Oriol (2005). No obstante, algunas universidades se apartan en mayor o menor medida de los cuatro ejes habituales en la mayoría de los planes de estudio (lenguaje musical, historia de la música, formación vocal e instrumental y didáctica aplicada). Además, no se encuentra una asignatura de didáctica entre las de la MEM, pero ello parece deberse a que la secuenciación de los contenidos está apoyada también en la asignatura obligatoria de $3^{\circ}$ 'Música y su aplicación didáctica', como sucede en la Universidad de Oviedo. Otro caso similar es la Universidad Internacional de La Rioja, con un plan de estudio bien secuenciado y fundamentado en las asignaturas obligatorias de $1^{\circ}$ y $2^{\circ}$.

Otra constante es continuar la secuencia habitual de la antigua especialidad, que suele empezar por las materias de formación técnico-musical. La excepción está representada por la Universidad Pública de Navarra y por la Universidad de Salamanca, donde las asignaturas didácticas se imparten antes que las técnicas. Se trata de una secuenciación diferente, donde priman los aspectos didácticos sobre los técnicos y formativos, con unos contenidos diversos y novedosos. Otro caso particular es el de la Universidad de Cádiz, donde no hay una asignatura formativa en lenguaje musical, aunque de esa parte parece encargarse la asignatura obligatoria 'Música y su didáctica'.

Se aprecia en estos planes de estudio una mayor diversificación de contenidos, con asignaturas que se apartan del modelo formativo-didáctico heredado de la diplomatura para dar cabida, en mayor medida que en las otras dos categorías, a materias relacionadas con las nuevas

@ Antonio Fernández Jiménez y Francisco A. Valdivia Sevilla. The content of this article is the sole responsibility of the authors. The Revista Electrónica de LEEME and Universitat de València are not liable for any legal actions that may arise involving the article's content. Revista Electrónica de LEEME - Lista Electrónica Europea de Música en la Educación-. http://ojs.uv.es/index/php/LEEME/index ISSN: 1575-9563. Editores: Universidad de Valencia y Jesús Tejada. Visibilidad de esta revista: SCOPUS, Emerging Sources Citation Index (Clarivate), EBSCO, CINDOC (CSIC), Citefactor, COPAC, Dialnet, DICE (CSIC), DOAJ, e-revistas (CSIC), EBSCO Premier, ERIH+, Gale Cengage Learning, IN-RECS, IRESIE, LATINDEX, MIAR, OCLC Worldcat, RESH, REDIB, RILM Core Journals, SUDOC, ULRICHS. Esta revista es de acceso libre mediante licencia Creative Commons 4.0 CC by. Política de archivado: etiqueta verde SHERPA-ROMEO. 


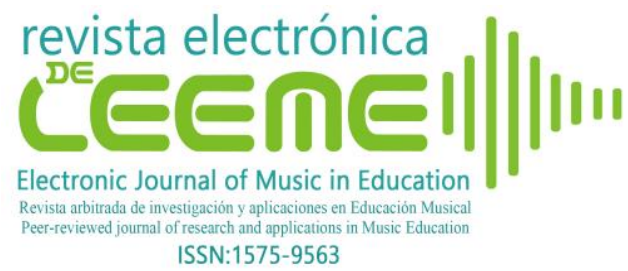

tecnologías, el movimiento y la creatividad. Así, seis universidades dedican una asignatura a las TIC: la Universidad Católica de Valencia ('Tecnologías de la información y la comunicación aplicadas a la educación musical'), la Universidad de Valladolid ('Tecnologías de la información y la comunicación aplicadas a la educación musical'), la Universitat de València ('Música y tecnologías de la información'), la Universidad de Gran Canaria ('Nuevas tecnologías aplicadas a la didáctica musical'), la Universidad Internacional de La Rioja ('Las tecnologías de la información y la comunicación aplicadas a la educación musical') y la Universidad de Vigo ('Novas tecnoloxías para a educación musical en primaria’).

También, aparecen planes de estudio donde hay asignaturas relacionadas con la creatividad. La Universidad de Castilla-La Mancha ofrece 'Prácticas musicales creativas', que propone el desarrollo de la creatividad a partir de la experiencia grupal. La Universidad de Burgos tiene otra asignatura bajo el nombre de 'Composición y creación musical', cuyos contenidos incluyen armonía, creación de acompañamientos armónicos y musicalización de textos. En la Universidad de Salamanca se encuentra 'Creación y selección de repertorio musical para el aula', y la Universidad Católica de Valencia cuenta con la asignatura 'Desarrollo de la creación e improvisación musical'.

Ocho universidades tienen asignaturas dedicadas específicamente al ritmo y al movimiento, sea con mención explícita de la danza, como en el caso de la Universidad de Salamanca (con dos), la Universidad de León, la Universidad de Vigo y la Universidad de Málaga, o a través de un enfoque basado en la rítmica corporal y gestual, el desarrollo psicomotor o la expresión corporal (Universidad Católica de Valencia, Universidad Católica San Antonio de Murcia, Universidad de Alicante, Universidad de Valencia y Universitat de Vic).

\subsection{Mención en un año $\left(4^{\circ}\right)$}

En estos planes de estudio - que básicamente tratan de condensar en un solo año toda la formación necesaria para obtener la MEM-, se pueden observar ciertas peculiaridades: en la Universidad de Sevilla, las prácticas escolares no son específicas de la MEM, y suman menos créditos que en otros planes de estudio; y la Universidad de Granada (sede Granada) no contempla una asignatura específica sobre didáctica de la música, sino que este aspecto se recoge en cada una de las asignaturas musicales centradas en aspectos técnico-musicales.

En la Universitat de les Illes Balears, a pesar de que la mención es propiamente en Música y Arte, no se advierten vínculos interdisciplinarios, lo cual incidiría en una relación con Plástica, por ejemplo, para una adecuada formación y la posterior intervención global y artística en el aula de Educación Primaria. También es en Artes la mención de la Universidad de Alcalá, concretamente en "Artes en Educación Primaria", pero no se aprecian asignaturas compartidas

@ Antonio Fernández Jiménez y Francisco A. Valdivia Sevilla. The content of this article is the sole responsibility of the authors. The Revista Electrónica de LEEME and Universitat de València are not liable for any legal actions that may arise involving the article's content. Revista Electrónica de LEEME - Lista Electrónica Europea de Música en la Educación-. http://ojs.uv.es/index/php/LEEME/index ISSN: 1575-9563. Editores: Universidad de Valencia y Jesús Tejada. Visibilidad de esta revista: SCOPUS, Emerging Sources Citation Index (Clarivate), EBSCO, CINDOC (CSIC), Citefactor, COPAC, Dialnet, DICE (CSIC), DOAJ, e-revistas (CSIC), EBSCO Premier, ERIH+, Gale Cengage Learning, IN-RECS, IRESIE, LATINDEX, MIAR, OCLC Worldcat, RESH, REDIB, RILM Core Journals, SUDOC, ULRICHS. Esta revista es de acceso libre mediante licencia Creative Commons 4.0 CC by. Política de archivado: etiqueta verde SHERPA-ROMEO. 


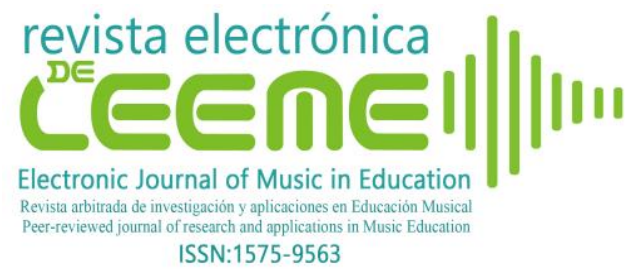

entre ambas áreas, con excepción de la asignatura 'Prácticum III', pero sin mostrar articulación entre ambas áreas. Por el contrario, en la Universidad de Almería la estructura de la MEM parece reflejar cuestiones corporativas en la inclusión de una asignatura del Área de Didáctica de la Expresión Plástica.

En la Universitat Jaume I, sólo hay una asignatura en la MEM, lo cual se compensa en parte con la presencia de dos asignaturas obligatorias en $2^{\circ}$ y $3^{\circ}$, que son respectivamente 'Música' y 'Didáctica de la expresión musical en Educación Primaria'. Es interesante la cantidad de créditos ECTS que se asignan a las prácticas escolares de la MEM, además de la obligatoriedad de las asignaturas de didáctica de las artes plásticas.

Hay asignaturas específicas dedicadas a la creatividad en la Universidad de Alcalá ('La creación musical en el aula de primaria'), la Universitat de Girona ('Práctica instrumental y creatividad') y la Universidad de Murcia ('Taller de creatividad musical', de solo 3 créditos ECTS).

Por otra parte, las nuevas tecnologías están presentes en la Universitat de Girona ('Oído y comprensión musical y uso de las tecnologías audiovisuales'); Universitat Jaume I ('Nuevas tecnologías aplicadas a la música'), y Universidad Autónoma de Madrid ('Formación musical IV: nuevas tecnologías aplicadas a la educación musical').

La universidad vasca Euskal Herriko Unibertsitatea ofrece una asignatura llamada 'Ritmo, movimiento y danza'. El movimiento también está presente en la Universitat de Barcelona, Universidad de Extremadura (sede Cáceres), Universidad de Zaragoza, Universidad de Murcia y Universidad de Córdoba (Centro adscrito Sagrado Corazón).

Por último, hay que destacar un campo interesante, y original, que solo contemplan los planes de estudio de tres universidades: el de la educación especial y la musicoterapia. Así, la Universidad de Almería ofrece 'Intervención musical en alumnado con necesidades educativas especiales', la Universidad de Córdoba (Centro adscrito Sagrado Corazón) 'Formación vocal y auditiva y efectos psico-educativos de la terapia musical', y la Universidad de Murcia 'Musicoterapia', si bien esta última solo cuenta con 3 créditos ECTS.

\section{Conclusiones}

Más allá de los criterios mínimos que establece la Orden ECI/3857/2007 (MEC, 2007) en cuanto a los créditos europeos para cada módulo, incluidas las menciones, las universidades combinan de manera distinta su MEM (Reyes, 2010). Esto se ha visto en la diversidad de modelos de estructura, ya no solo en cuanto a la secuenciación y temporalización de las asignaturas, sino en el reparto de créditos dentro de la MEM, que se traduce en el hecho de que

@ Antonio Fernández Jiménez y Francisco A. Valdivia Sevilla. The content of this article is the sole responsibility of the authors. The Revista Electrónica de LEEME and Universitat de València are not liable for any legal actions that may arise involving the article's content. Revista Electrónica de LEEME - Lista Electrónica Europea de Música en la Educación-. http://ojs.uv.es/index/php/LEEME/index ISSN: 1575-9563. Editores: Universidad de Valencia y Jesús Tejada. Visibilidad de esta revista: SCOPUS, Emerging Sources Citation Index (Clarivate), EBSCO, CINDOC (CSIC), Citefactor, COPAC, Dialnet, DICE (CSIC), DOAJ, e-revistas (CSIC), EBSCO Premier, ERIH+, Gale Cengage Learning, IN-RECS, IRESIE, LATINDEX, MIAR, OCLC Worldcat, RESH, REDIB, RILM Core Journals, SUDOC, ULRICHS. Esta revista es de acceso libre mediante licencia Creative Commons 4.0 CC by. Política de archivado: etiqueta verde SHERPA-ROMEO. 


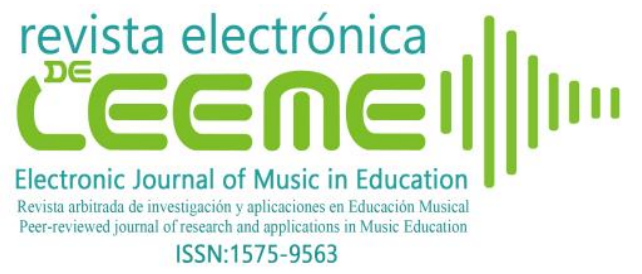

algunos planes de estudio están formados solamente por asignaturas optativas, encontrándose ejemplos en cada una de las tres categorías, como es el caso de la Universitat Ramon Llull, la Universidad de Vigo y la Universidad de Zaragoza.

Otros planes de estudio están formados por asignaturas optativas (en torno a los 24 créditos ECTS) y créditos procedentes de la asignatura dedicada a las prácticas escolares, para completar los 30 créditos ECTS que recoge la citada Orden, con ejemplos en cada una de las tres categorías, como es el caso del plan de estudio de la Universidad Rey Juan Carlos, la Universidad de Granada (ambas sedes) y la Universidad de Castilla-La Mancha. En este modelo de MEM formada por créditos de asignaturas optativas y créditos de las prácticas escolares aparece el caso de la Universitat Jaume I, que otorga el mayor peso de la MEM a las Prácticas Escolares, quedando solo 6 créditos ECTS para una asignatura optativa, aunque cuenta con dos asignaturas obligatorias. Resulta destacable la poca formación musical destinada a la futura persona Graduada en Educación Primaria con MEM (desde el prisma de las asignaturas optativas de la Mención), lo cual refleja un modelo de formación musical complementaria que capacita para ofrecer respuestas didácticas en el aula de música de Educación Primaria (Iotova y Siebenaler, 2018). Este caso resulta ser ejemplificador, llevado al extremo, del modelo de docente de música propiciado por la convergencia europea de los estudios universitarios, esto es, un docente generalista con poca formación musical, pero que puede cubrir necesidades del centro educativo en otras asignaturas (Aróstegui y Cisneros-Cohernour, 2010).

Finalmente, la diversidad reflejada en los planes de estudio, así como la triple estructura observada en la MEM, invita a desarrollar una investigación que estudie las fortalezas y debilidades de una temporalización de la MEM repartida durante varios años del Grado o aglutinada en el último curso de la titulación, es decir, abordar el perfil de egreso de los titulados, así como el perfil de las personas que cursan la MEM.

\section{Financiación y agradecimientos}

Este artículo es parte del Proyecto de Investigación I+D EDU2017-84782 sobre Formación de Profesorado y Música en la Sociedad y la Economía del Conocimiento, correspondiente al Programa Estatal de Fomento de la Investigación Científica y Técnica de Excelencia, financiado por el Ministerio de Economía y Competitividad.

\section{Referencias}

Aróstegui, J.L. (Ed.). (2010). Formación del profesorado de música: Planes de estudio en Europa y América Latina (Monográfico). Profesorado. Revista de Currículum y Formación de Profesorado, 14(2), 3-7. Recuperado de https://bit.ly/2E1gGon

Aróstegui, J.L. (Ed.). (2011). Educating Music Teachers for the 21st Century. Rotterdam: Sense Publishers.

@ Antonio Fernández Jiménez y Francisco A. Valdivia Sevilla. The content of this article is the sole responsibility of the authors. The Revista Electrónica de LEEME and Universitat de València are not liable for any legal actions that may arise involving the article's content. Revista Electrónica de LEEME - Lista Electrónica Europea de Música en la Educación-. http://ojs.uv.es/index/php/LEEME/index ISSN: 1575-9563. Editores: Universidad de Valencia y Jesús Tejada. Visibilidad de esta revista: SCOPUS, Emerging Sources Citation Index (Clarivate), EBSCO, CINDOC (CSIC), Citefactor, COPAC, Dialnet, DICE (CSIC), DOAJ, e-revistas (CSIC), EBSCO Premier, ERIH+, Gale Cengage Learning, IN-RECS, IRESIE, LATINDEX, MIAR, OCLC Worldcat, RESH, REDIB, RILM Core Journals, SUDOC, ULRICHS. Esta revista es de acceso libre mediante licencia Creative Commons 4.0 CC by. Política de archivado: etiqueta verde SHERPA-ROMEO. 


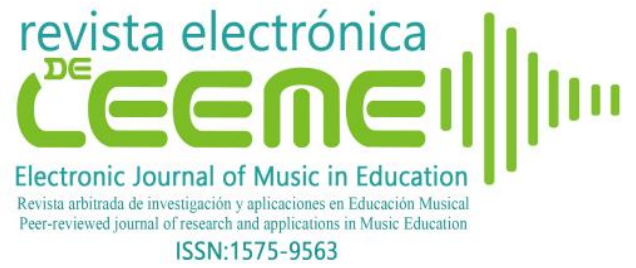

Aróstegui, J.L. y Cisneros-Cohernour, E. (2010). Reflexiones en torno a la formación del profesorado de música a partir del análisis documental de los planes de estudio en Europa y América Latina. Profesorado. Revista de Currículum y Formación de Profesorado, 14(2), 179-189. Recuperado de https://bit.ly/2XPHOxO

Belletich, O., Ángel-Alvarado, R. y Wilhelmi, M.R. (2017). Normas epistémicas en la formación musical del maestro de educación primaria. Journal for Educators, Teachers and Trainers, 8(1), 199-213. Recuperado de https://bit.ly/33QX0OX

Iotova, A.I. y Siebenaler, D. (2018). La formación del profesorado de música en la Universidad Complutense de Madrid y la Universidad Estatal de California: Un estudio comparado. Profesorado. Revista de Currículum y Formación de Profesorado, 22(3), 295-315. doi: https://doi.org/10.30827/profesorado.v22i3.8003

López, N., Madrid, D. y de Moya, M.V. (2017). La formación musical en los planes de estudios para maestros de Primaria en la Universidad de Castilla-La Mancha. Estudios pedagógicos (Valdivia), 43(1), 423-438. doi: http://dx.doi.org/10.4067/S0718$\underline{07052017000100024}$

Ministerio de Educación y Ciencia (2007). ORDEN ECI/3857/2007, de 27 de diciembre, por la que se establecen los requisitos para la verificación de los títulos universitarios oficiales que habiliten para el ejercicio de la profesión de Maestro en Educación Primaria. BOE (29/12/2007), núm.312, referencia 22449, pp.53747-53750.

Oriol, N. (2005). La música en las Enseñanzas de Régimen General en España y su evolución en el siglo XX y comienzos del XXI. Revista Electrónica de LEEME, 16, 1-33. Recuperado de https://bit.ly/3ixLGvb

Reyes, M.L. (2010). Evaluación de los planes de estudio de formación del profesorado de educación musical. Profesorado. Revista de Currículum y Formación de Profesorado, 14(2), 67-81. Recuperado de https://bit.ly/3fPzhkA

Universitat Autònoma de Barcelona (2020). Plan de Estudios de la titulación de Maestro/a en Educación Primaria. Recuperado de: https://bit.ly/2DZyBM9

Universidad Autónoma de Madrid (2020). Plan de Estudios de la titulación de Maestro/a en Educación Primaria. Recuperado de: https://bit.ly/2DZyO1T

Universidad de Alcalá (2020). Plan de Estudios de la titulación de Maestro/a en Educación Primaria. Recuperado de: https://bit.ly/2DWFpKN

@ Antonio Fernández Jiménez y Francisco A. Valdivia Sevilla. The content of this article is the sole responsibility of the authors. The Revista Electrónica de LEEME and Universitat de València are not liable for any legal actions that may arise involving the article's content. Revista Electrónica de LEEME - Lista Electrónica Europea de Música en la Educación-. http://ojs.uv.es/index/php/LEEME/index ISSN: 1575-9563. Editores: Universidad de Valencia y Jesús Tejada. Visibilidad de esta revista: SCOPUS, Emerging Sources Citation Index (Clarivate), EBSCO, CINDOC (CSIC), Citefactor, COPAC, Dialnet, DICE (CSIC), DOAJ, e-revistas (CSIC), EBSCO Premier, ERIH+, Gale Cengage Learning, IN-RECS, IRESIE, LATINDEX, MIAR, OCLC Worldcat, RESH, REDIB, RILM Core Journals, SUDOC, ULRICHS. Esta revista es de acceso libre mediante licencia Creative Commons 4.0 CC by. Política de archivado: etiqueta verde SHERPA-ROMEO. 
Universidad de Alicante (2020). Plan de Estudios de la titulación de Maestro/a en Educación Primaria. Recuperado de: https://bit.ly/3agY9kh

Universidad de Almería (2020). Plan de Estudios de la titulación de Maestro/a en Educación Primaria. Recuperado de: https://bit.ly/33OIdVb

Universitat de Barcelona (2020). Plan de Estudios de la titulación de Maestro/a en Educación Primaria. Recuperado de: https://bit.ly/2F8C4IX

Universidad de Burgos (2020). Plan de Estudios de la titulación de Maestro/a en Educación Primaria. Recuperado de: https://bit.ly/2XTkC1I

Universidad de Cádiz (2020). Plan de Estudios de la titulación de Maestro/a en Educación Primaria. Recuperado de: https://bit.ly/3iABana

Universidad Camilo José Cela (2020). Plan de Estudios de la titulación de Maestro/a en Educación Primaria. Recuperado de: https://bit.ly/2DT4xCa

Universidad de Castilla-La Mancha (2020). Plan de Estudios de la titulación de Maestro/a en Educación Primaria. Recuperado de: https://bit.ly/2DTZbGE

Universidad Católica San Antonio de Murcia (2020). Plan de Estudios de la titulación de Maestro/a en Educación Primaria. Recuperado de: https://bit.ly/3gPb9Qo

Universidad Católica de Valencia (2020). Plan de Estudios de la titulación de Maestro/a en Educación Primaria. Recuperado de: https://bit.ly/3kKKM0D

Universidad Complutense de Madrid (2020). Plan de Estudios de la titulación de Maestro/a en Educación Primaria. Recuperado de: https://bit.ly/2DOrSFl

Universidad de Córdoba (2020). Plan de Estudios de la titulación de Maestro/a en Educación Primaria. Recuperado de: https://bit.ly/3gVl8Uo

Universidad de Córdoba (Centro adscrito Sagrado Corazón) (2020). Plan de Estudios de la titulación de Maestro/a en Educación Primaria. Recuperado de: https://bit.ly/33SyPzS

Universidad de Extremadura (sede Cáceres) (2020). Plan de Estudios de la titulación de Maestro/a en Educación Primaria. Recuperado de: https://bit.ly/2DEIShk

Universidad Francisco de Vitoria (2020). Plan de Estudios de la titulación de Maestro/a en Educación Primaria. Recuperado de: https://bit.ly/31JykoZ

Universitat de Girona (2020). Plan de Estudios de la titulación de Maestro/a en Educación Primaria. Recuperado de: https://bit.ly/2PMBu5K

@ Antonio Fernández Jiménez y Francisco A. Valdivia Sevilla. The content of this article is the sole responsibility of the authors. The Revista Electrónica de LEEME and Universitat de València are not liable for any legal actions that may arise involving the article's content. Revista Electrónica de LEEME - Lista Electrónica Europea de Música en la Educación-. http://ojs.uv.es/index/php/LEEME/index ISSN: 1575-9563. Editores: Universidad de Valencia y Jesús Tejada. Visibilidad de esta revista: SCOPUS, Emerging Sources Citation Index (Clarivate), EBSCO, CINDOC (CSIC), Citefactor, COPAC, Dialnet, DICE (CSIC), DOAJ, e-revistas (CSIC), EBSCO Premier, ERIH+, Gale Cengage Learning, IN-RECS, IRESIE, LATINDEX, MIAR, OCLC Worldcat, RESH, REDIB, RILM Core Journals, SUDOC, ULRICHS. Esta revista es de acceso libre mediante licencia Creative Commons 4.0 CC by. Política de archivado: etiqueta verde SHERPA-ROMEO. 
Universidad de Gran Canaria (2020). Plan de Estudios de la titulación de Maestro/a en Educación Primaria. Recuperado de: https://bit.ly/2PKguMS

Universidad de Granada (sede Granada) (2020). Plan de Estudios de la titulación de Maestro/a en Educación Primaria. Recuperado de: https://bit.ly/3gLQtc2

Universidad de Granada (sede Melilla) (2020). Plan de Estudios de la titulación de Maestro/a en Educación Primaria. Recuperado de: https://bit.ly/3iwkBIU

Universidad de Huelva (2020). Plan de Estudios de la titulación de Maestro/a en Educación Primaria. Recuperado de: https://bit.ly/3fRbK2A

Universidad del País Vasco (2020). Plan de Estudios de la titulación de Maestro/a en Educación Primaria. Recuperado de: https://bit.ly/31HVaNT

Universitat de les Illes Balears (2020). Plan de Estudios de la titulación de Maestro/a en Educación Primaria. Recuperado de: https://bit.ly/3ajDjR7

Universidad Internacional de La Rioja (2020). Plan de Estudios de la titulación de Maestro/a en Educación Primaria. Recuperado de: https://bit.ly/31JDEc7

Universidad de Jaén (2020). Plan de Estudios de la titulación de Maestro/a en Educación Primaria. Recuperado de: https://bit.ly/30Pil9F

Universitat Jaume I (2020). Plan de Estudios de la titulación de Maestro/a en Educación Primaria. Recuperado de: https://bit.ly/3kxlYch

Universidad de La Laguna (2020). Plan de Estudios de la titulación de Maestro/a en Educación Primaria. Recuperado de: https://bit.ly/30OOttT

Universidad de León (2020). Plan de Estudios de la titulación de Maestro/a en Educación Primaria. Recuperado de: https://bit.ly/2PKBlQv

Universitat de Lleida (2020). Plan de Estudios de la titulación de Maestro/a en Educación Primaria. Recuperado de: https://bit.ly/3kFcSdm

Universidad de Málaga (2020). Plan de Estudios de la titulación de Maestro/a en Educación Primaria. Recuperado de: https://bit.ly/2FlBlVb

Universidad de Murcia (2020). Plan de Estudios de la titulación de Maestro/a en Educación Primaria. Recuperado de: https://bit.ly/30PLHVB

Universidad de Oviedo (2020). Plan de Estudios de la titulación de Maestro/a en Educación Primaria. Recuperado de: https://bit.ly/3akwxLa

@ Antonio Fernández Jiménez y Francisco A. Valdivia Sevilla. The content of this article is the sole responsibility of the authors. The Revista Electrónica de LEEME and Universitat de València are not liable for any legal actions that may arise involving the article's content. Revista Electrónica de LEEME - Lista Electrónica Europea de Música en la Educación-. http://ojs.uv.es/index/php/LEEME/index ISSN: 1575-9563. Editores: Universidad de Valencia y Jesús Tejada. Visibilidad de esta revista: SCOPUS, Emerging Sources Citation Index (Clarivate), EBSCO, CINDOC (CSIC), Citefactor, COPAC, Dialnet, DICE (CSIC), DOAJ, e-revistas (CSIC), EBSCO Premier, ERIH+, Gale Cengage Learning, IN-RECS, IRESIE, LATINDEX, MIAR, OCLC Worldcat, RESH, REDIB, RILM Core Journals, SUDOC, ULRICHS. Esta revista es de acceso libre mediante licencia Creative Commons 4.0 CC by. Política de archivado: etiqueta verde SHERPA-ROMEO. 
Universidad de Oviedo (Centro adscrito privado Facultad Padre Ossó) (2020). Plan de Estudios de la titulación de Maestro/a en Educación Primaria. Recuperado de: https://bit.ly/3gS6cGu

Universidad Pontificia de Salamanca (2020). Plan de Estudios de la titulación de Maestro/a en Educación Primaria. Recuperado de: https://bit.ly/2XVHXjf

Universidad Pública de Navarra (2020). Plan de Estudios de la titulación de Maestro/a en Educación Primaria. Recuperado de: https://bit.ly/2XOFQ0L

Universitat Ramon Llull (2020). Plan de Estudios de la titulación de Maestro/a en Educación Primaria. Recuperado de: https://bit.ly/3gQntQl

Universidad Rey Juan Carlos (2020). Plan de Estudios de la titulación de Maestro/a en Educación Primaria. Recuperado de: https://bit.ly/3ajDD2v

Universitat Rovira i Virgili (2020). Plan de Estudios de la titulación de Maestro/a en Educación Primaria. Recuperado de: https://bit.ly/2HYq8vp

Universidad de Salamanca (2020). Plan de Estudios de la titulación de Maestro/a en Educación Primaria. Recuperado de: https://bit.ly/3kDobmt

Universidad de Santiago de Compostela (2020). Plan de Estudios de la titulación de Maestro/a en Educación Primaria. Recuperado de: https://bit.ly/3kDWeeo

Universidad de Sevilla (2020). Plan de Estudios de la titulación de Maestro/a en Educación Primaria. Recuperado de: https://bit.ly/31LLTEh

Universitat de València (2020). Plan de Estudios de la titulación de Maestro/a en Educación Primaria. Recuperado de: https://bit.ly/3fNcvdj

Universidad de Valladolid (2020). Plan de Estudios de la titulación de Maestro/a en Educación Primaria. Recuperado de: https://bit.ly/31LM8iF

Universitat de Vic (2020). Plan de Estudios de la titulación de Maestro/a en Educación Primaria. Recuperado de: https://bit.ly/33RrjFp

Universidad de Vigo (2020). Plan de Estudios de la titulación de Maestro/a en Educación Primaria. Recuperado de: https://bit.ly/2Ck0qOU

Universidad de Zaragoza (2020). Plan de Estudios de la titulación de Maestro/a en Educación Primaria. Recuperado de: https://bit.ly/3agboBI

@ Antonio Fernández Jiménez y Francisco A. Valdivia Sevilla. The content of this article is the sole responsibility of the authors. The Revista Electrónica de LEEME and Universitat de València are not liable for any legal actions that may arise involving the article's content. Revista Electrónica de LEEME - Lista Electrónica Europea de Música en la Educación-. http://ojs.uv.es/index/php/LEEME/index ISSN: 1575-9563. Editores: Universidad de Valencia y Jesús Tejada. Visibilidad de esta revista: SCOPUS, Emerging Sources Citation Index (Clarivate), EBSCO, CINDOC (CSIC), Citefactor, COPAC, Dialnet, DICE (CSIC), DOAJ, e-revistas (CSIC), EBSCO Premier, ERIH+, Gale Cengage Learning, IN-RECS, IRESIE, LATINDEX, MIAR, OCLC Worldcat, RESH, REDIB, RILM Core Journals, SUDOC, ULRICHS. Esta revista es de acceso libre mediante licencia Creative Commons 4.0 CC by. Política de archivado: etiqueta verde SHERPA-ROMEO. 